\title{
Infected Subdural Effusion Associated with Resolving Subdural Hematoma
}

\section{-Case Report-}

\author{
Nobuhiko AOKI, Tatsuo SAKAI, Akihiro OIKAWA, \\ Touichiro TAKIZAWA*, and Tsuneo SHISHIDO**
}

Departments of Neurosurgery and *Pathology, Tokyo Metropolitan Ohkubo Hospital, Tokyo;
${ }^{* *}$ Department of Neurosurgery, Tokyo Metropolitan Matsuzawa Hospital, Tokyo

\begin{abstract}
A 70-year-old male presented with rapid neurological deterioration and fever 3 months after suffering a closed head trauma. He underwent craniotomy for possible subdural empyema based on computed tomography and clinical findings. Dural incision revealed an outer membrane typical of chronic subdural hematoma which covered a clear, yellowish fluid containing Campylobacter fetus. Histological examination confirmed the capsule of the hematoma, with a necrotic focus infiltrated by neutrophiles. Administration of intravenous imipenem and topical tobramycin and cefalothin achieved total resolution of his neurological deficits. Development of the infected subdural effusion was probably secondary to bacterial infection in the pre-existing chronic subdural hematoma in the resolving stage. The presence of the hematoma capsule always carries the risk of development of an infectious focus.
\end{abstract}

Key words: subdural effusion, subdural empyema, subdural hematoma, Campylobacter fetus

\section{Introduction}

Head injury is frequently complicated by subdural fluid collections such as subdural hygroma, subdural effusion, subdural hematoma, and subdural empyema. However, a combination of these pathological processes is rare. For example, only two adult patients with bacterial infection of chronic subdural hematoma have been reported since computed tomography (CT) was introduced. ${ }^{2,3)}$ We describe a patient who underwent craniotomy under a diagnosis of possible subdural empyema, but dural incision disclosed the outer membrane of chronic subdural hematoma, under which subdural effusion with positive bacterial culture was demonstrated.

\section{Case Report}

A 70-year-old male with no significant past history fell while very drunk, striking his left occipital region on May 21, 1995. On arrival at our emergency room, he had altered consciousness alone, which resolved within a week after admission. He had no

Received August 21, 1996;

Accepted April 2, 1997 open scalp wounds, but a linear fracture in the left occipital region and cerebral contusion in the right frontal region were observed. However, CT showed no subdural hematoma or effusion in the acute stage. Laboratory data, including serum biochemistry and urinalysis, showed no abnormalities. He was discharged from our hospital on June 6 , and enjoyed a healthy life until September 6, when he suffered high-grade fever and headache.

He presented at our outpatient clinic in the morning of September 7. A physical examination revealed clear consciousness and mild hemiparesis on the left side. A precontrast CT scan showed a thin subdural fluid collection (Fig. 1). Routine blood analysis revealed definite signs of inflammation, evidenced by a white blood cell count of $12,600 / \mathrm{mm}^{3}$, and Creactive protein of $19.8 \mathrm{mg} / \mathrm{dl}$. His temperature persisted up to $39.5^{\circ} \mathrm{C}$. In the evening on the day of admission, he became delirium, and had at least 15 times of convulsive attacks. Repeat precontrast CT showed no enlargement of the subdural fluid collection.

Emergent craniotomy in the right parietal region was performed under a diagnosis of possible subdural empyema. Dural incision disclosed a $2 \mathrm{~mm}$ - 


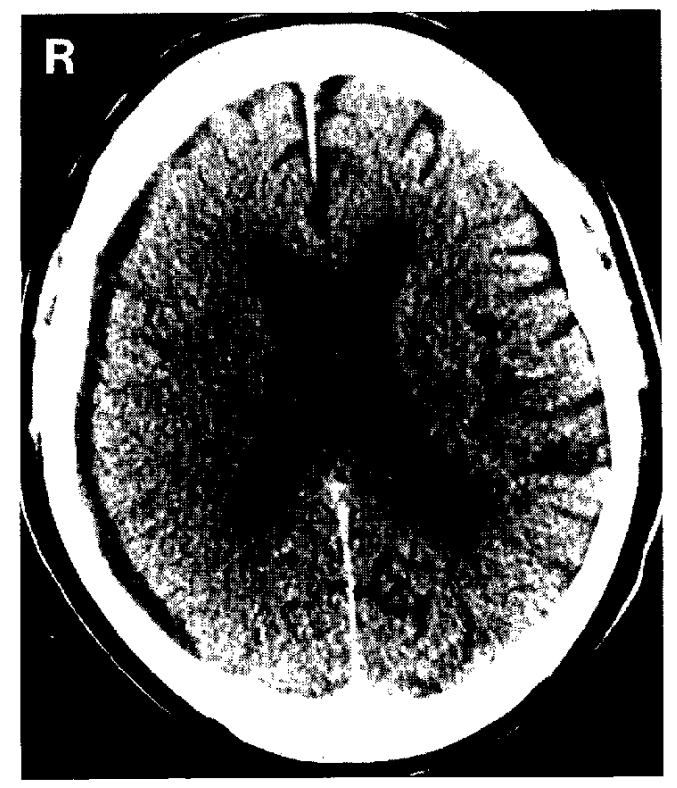

Fig. 1 Precontrast computed tomography scan on readmission, showing a thin layer of subdural fluid collection on the right.

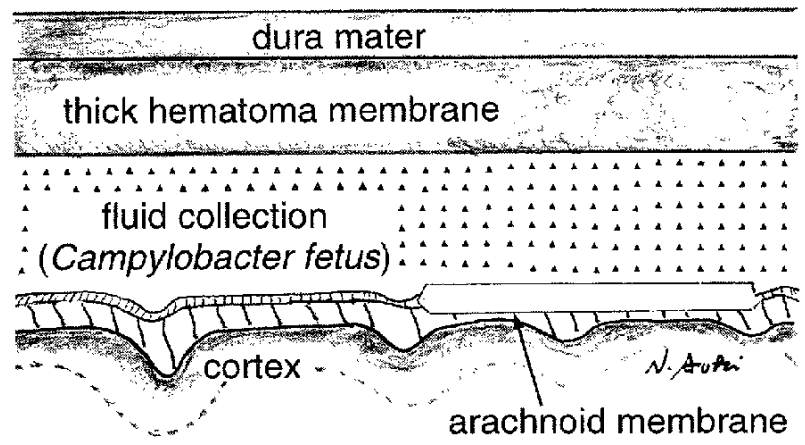

Fig. 2 Schematic drawing of the operative findings.

thick membrane which appeared to be typical of chronic subdural hematoma. Incision of the membrane allowed a clear, yellowish fluid gush out under pressure. There was no membranous structure on the whitish, thickened arachnoid membrane (Fig. 2). The subdural fluid was irrigated with physiological saline, and a drain was placed in the subdural space. His postoperative condition was unchanged, and he had persistent delirium, mild left hemiparesis, and fever.

Culture of the subdural fluid identified Campylobacter fetus, so imipenem $11 \mathrm{~g}$ twice a day, for 8 days) was administered intravenously. In addition, the subdural space was irrigated with physiological
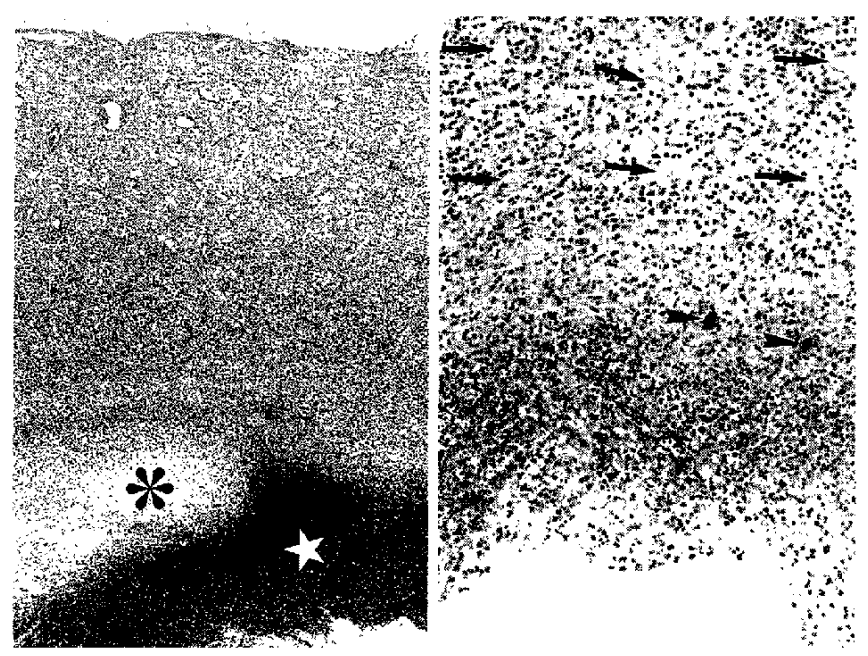

Fig. 3 Photomicrographs of the subdural membrane, showing thick fibroblastic granulation tissue, including a necrotic focus (asterisk) with infiltration of neutrophiles suggestive of pre-existing pus, and hematoma (star) (left: HE stain, $\times 40$ ); and rich vascular channels (arrows) and deposits of hemosiderin (arrowheads), characteristic of chronic subdural hematoma (right: HE stain, $\times 100$ ).

saline containing tobramycin (10 mg once a day, for 10 days) and cefalothin (100 mg once a day, for 10 days) through the subdural drain. His consciousness became clear, and the hemiparesis and fever resolved 10 days after surgery. CT showed the subdural fluid collection had disappeared. No examination of cerebrospinal fluid was carried out during the pre- or postoperative periods. He was discharged without neurological deficits on October 6.

Histological examination of the operative specimen underneath the dura mater revealed thick fibroblastic granulation tissue, including a necrotic focus infiltrated by neutrophiles suggestive of pre-existing pus and hematoma on the inner side (Fig. 3 left), and rich vascular channels and deposits of hemosiderin, characteristic of the outer membrane of chronic subdural hematoma (Fig. 3 right).

\section{Discussion}

The present patient underwent emergent craniotomy because of rapid neurological deterioration, despite CT showing only a thin subdural fluid collection. Dural incision disclosed the presence of a chronic subdural hematoma membrane, but the fluid collection was not liquid hematoma but a clear, yellowish fluid containing Campylobacter fetus. In- 
Table 1 Adult cases of infected subdural hematoma

\begin{tabular}{ccccc}
\hline Author (Year) & $\begin{array}{c}\text { Age/ } \\
\text { Sex }\end{array}$ & Organism & $\begin{array}{c}\text { Causative } \\
\text { factor }\end{array}$ & Outcome \\
\hline $\begin{array}{c}\text { Kaminogo et al. } \\
(1984)^{3 /}\end{array}$ & $76 / \mathrm{F}$ & $\begin{array}{c}\text { Escherichia } \\
\text { coli }\end{array}$ & $\begin{array}{c}\text { agranuro- } \\
\text { cytosis } \\
\text { cholecystitis }\end{array}$ & excellent \\
$\begin{array}{c}\text { Hirano et al. } \\
(1995)^{23}\end{array}$ & $86 / \mathrm{M}$ & $\begin{array}{c}\text { Escherichia } \\
\text { coli }\end{array}$ \\
$\begin{array}{c}\text { Present case } \\
\text { 70/M }\end{array}$ & $\begin{array}{c}\text { Campylo- } \\
\text { bacter fetus }\end{array}$ & not definite & excellent \\
\hline
\end{tabular}

fected subdural effusion seems to be a more suitable description than subdural empyema. The patient had suffered head injury with skull fracture 3 months prior to readmission, but there was no CT evidence of the presence of chronic subdural hematoma since no further CT examinations were performed after his first discharge. However, the operative and histological findings strongly indicated the presence of chronic subdural hematoma. The absence of liquid hematoma under the subdural hematoma membrane at surgery suggested that the chronic subdural hematoma had resolved without causing neurological symptoms. ${ }^{5,6]}$

Histological examination detected pre-existing pus foci in the membrane, so the subdural effusion was probably derived from the infected subdural hematoma membrane. Two previous cases of bacterial infection of the subdural hematoma membrane, ${ }^{2,3)}$ as well as metastasis of malignant cells to chronic subdural hematoma, ${ }^{1,47}$ have been reported before (Table 1). Our patient was examined for susceptibility to bacterial infection, but laboratory data failed to reveal any abnormalities, such as diabetes mellitus or immunocompromise. The causative organism was the Gram-negative rod, Campylobacter fetus, which usually inhabits the gastrointestinal tract. The route of bacterial spread to the hematoma membrane was not established, but hematogenic infection is suspected due to the nonpenetrating nature of previous head trauma without open scalp wounds, the skull fracture not involving air-containing structures, and the gastrointestinal habits of the causative bacterium. Chronic subdural hematoma has a variety of clinical courses, including apoplectic progression and spontaneous resolution. ${ }^{5,6]}$ The most important aspect of the present case is that the presence of the hematoma capsule always involves the risk of bacterial infection. Chronic subdural hematoma, even in the resolving stage, may be a causative factor for the development of subdural empyema.

Chronic subdural hematoma membrane is a potential site for bacterial infection, because it contains rich vascular capillary beds. Infected subdural effusion may result in fulminant neurological deterioration, even if only a thin layer of fluid collection is present.

\section{References}

1) Cheng CL, Greenbert J, Hoover LA: Prostate adenocarcinoma metastatic to chronic subdural hematoma membranes. J Neurosurg 68: 642-644, 1988

2) Hirano A, Takamura $T$, Murayama $N$, Ohyama $K$, Matsumura S, Niwa J: [Subdural abscess following chronic subdural hematoma]. No Shinkei Geka 23: 643-646, 1995 (Jpn, with Eng abstract)

3) Kaminogo M, Kurihara M, Kawano $T$, Mori K, Yasuda M: [A case of infected subdural hematoma (subdural empyema) secondary to septicemia caused by agranurocytosis]. No Shinkei Geka 12; 353-357, 1984 (Jpn, with Eng abstract)

4) McKenzie CR, Rengachery SS, McGreger DH, Dixon AY, Suskind DL: Subdural hematoma associated with metastatic neoplasms. Neurosurgery 27:619-625, 1990

5) Naganuma H, Fukamachi H, Kawakami M, Misumi S, Nakajima H, Wakao T: Spontaneous resolution of chronic subdural hematomas. Neurosurgery 19: 794798,1986

6) Nakamura $\mathrm{N}$, Ogawa $\mathrm{T}$, Hashimoto $\mathrm{T}$, Yuki $\mathrm{K}$, Kobayashi S: [Reevaluation on resolving subdural hematoma]. Neurol Med Chir (Tokyo) 21: 491-500, 1981 (Jpn, with Eng abstract)

7) Reyes MG, Hosmi MF, Mangkornkanong M. Stone J, Glick RP: Malignant lymphoma presenting as a chronic subdural hematoma. Surg Neurol 33: 35-36, 1990

Address reprint requests to: N. Aoki, M.D., Department of Neurosurgery, Tokyo Metropolitan Ohkubo Hospital, 2-44-1 Kabuki-cho, Shinjuku-ku, Tokyo 160, Japan. 